\title{
A Study of the Best Applicable Marketing Strategies for PICOMS International University College Malaysia
}

\author{
Datuk Dr Mahamad Zubir bin Seeht Saad \\ Pusrawi International College of Medical Sciences \\ DOI: $10.31364 / \mathrm{SCIRJ} / \mathrm{v} 6 . \mathrm{i} 7.2018 . P 0718540$ \\ http://dx.doi.org/10.31364/SCIRJ/v6.i7.2018.P0718540
}

\begin{abstract}
PICOMS International University College Malaysia has been adopting some marketing and advertising strategies as well as methods throughout the recent years in its efforts to increase recruitment of new students into its wide variety of courses offered. This research is being carried out to review the effectiveness of its current marketing and advertising strategies, before looking into further refining its marketing and advertising strategies by incorporating other means of advertisements and marketing practices. For the purpose of this research, a questionnaire survey has been designed and passed on to a total of 800 respondents where 400 are new students along with their 400 parents of the July 2018 intake to evaluate the existing marketing practices and seek for further improvements.
\end{abstract}

Index Terms - Marketing, Advertising, Methods, Practices, Strategies, Student recruitment, PICOMS

\section{Introduction}

For all profit-making organisations, marketing has always been seen as a main medium to leverage the sales of the organisations' offerings, regardless whether it concerns intangible services or tangible products (Jager, 2007). The same applies for PICOMS which is one of the most reputable educational institution in Malaysia focusing on offering a wide range of courses to students. In line with other profit-making organisations, PICOMS has always been occupied in better marketing and advertising itself towards the education community in Malaysia.

The number of educational institutions in Malaysia have been steadily increasing over the years due to increasing globalisation rates which leads education institutions to expand their business rapidly out of traditional means (Terkan, 2014). Wijaya and Krismiyati (2013) have also reaffirmed such increasing competitions among higher learning education institutions; with Wee and Thinavan (2013) confirming such a situation specifically within the Malaysia context due to the policies of the Malaysian government and the increasing costs for students to study abroad.

This means that the management of PICOMS would need to always position itself properly in order to sustain its student recruitments. When a student wants to further his or her studies in tertiary fields, there would be a lot of choices in terms of educational institutions for him or her to choose from. This is one of the reasons why PICOMS would need to craft out its own competitive advantages so that it would be able to better position itself to attract students from not signing up with other educational institutions but PICOMS.

Therefore, throughout these years, PICOMS has been adopting marketing practices and tools within both traditional mediums such as billboards, radio, television, corporate social responsibility programmes; up to digital marketing means such as Facebook and the Whatssap messenger. Realising that the only constant in this world is change, the management of PICOMS is continuously striving to 
identify up to date advertising means aimed at sustaining its student recruitment activities which translates to increased sales and profits.

Therefore, the purpose of this study is to firstly gather feedback from the institution's students as well as the students' parents to seek for their views on the effectiveness of PICOMS' current advertising and marketing practices. The next aim of this study would be to seek for recommendations on how the management can further improve and sustain the performance of its marketing and advertising practices.

\section{Research Elaborations}

\subsection{Problem Statement}

The main driver of this paper lies at increased competitions among educational institutions in Malaysia and the need for the management of PICOMS to sustain or at least maintain its new students' recruitment figures. Wong and Hamali (2006) explained that the demand of private institutions of higher learnings have been rising due to the incompetency of public education institutions to cater towards the increasing demand for higher education levels. And such phenomenon has been continuously plaguing Malaysia where the number of private institutions of higher learnings are consistently rising (Wee and Thinavan, 2013). This consequently lead to more institutions needing to grab a share of the same pie which result in lesser portions for each. And to win such competition, institutions such as PICOMS would need to look for competitive edges that can give them an edge over their competitors and to successfully entice new students to choose them instead of their competitors. That is why it is vital for the management of PICOMS to review its existing marketing and advertising practices and appraise their compatibilities within the intensified competitive arena; and further refine their strategies and practices accordingly.

\subsection{Research Questions}

This study is being revolved around two research questions of:

1. How effective are the existing marketing and advertising practices employed by PICOMS?

2. How could these been further refined or improved in order for PICOMS to sustain its student recruitment figures?

\subsection{Literature Review}

Advertising, according to Jefkins (1992), assists in fleshing out the most enticing message to the target audiences for a profit making organisational offering through the least possible costs. It is how organisations are promoting their offerings to the intended public audiences by expecting to increase their sales of those offerings through the attention drawn (Kotler, 2002). Trehan and Trehan (2011) opined that, profit making organisations would need to be in a persuasive and attracting position to approach markets which are generally being controlled by customers in order to have their offerings being sold to those customers. Advertising is essentially how organisations reach out to their intended customers to entice the customers to resort to purchasing their offerings instead of those of their competitors, which can be done through various mediums such as traditional means as well as the modern digital means. Terkan (2014) further explained that the advertisement mediums chosen are typically dependent on the nature of the organisational offerings. Some tangible goods may be suitable to be advertised using broadcast media, whereas certain intangible services could be more suitable through digital advertisements.

According to Terkan (2014), there are a lot of benefits that can be associated with advertising, and it can be segregated according to the society, the manufacturers, and also the consumers. Towards the manufacturers, advertising assists them in promoting their products so increase awareness of the same among the target audiences, which consequently lead to increased demand, sales and 
lastly production. As for the consumers, advertising actually assisted them to save more of their precious time by leading them towards their products or services of interests only, as consumers can do their homework before going shopping rather than waste time choosing while being at the shopping destinations. Terkan (2014) also clarified that advertisements actually help consumers to save more, since organisations are competing among themselves to give higher values to the consumers through the lowest possible costs. Last but not least, the act of advertising also benefits the society by means of providing more job opportunities for the people; as well as improving the standards of living for the society as a whole since organisations are always competing to offer the best possible values to the consumers.

Kotler (2002) also shared the flop side of advertising through the presentation of some weaknesses of advertisements. In some cases, advertising could cause the price of organisational offerings to be higher than normal, due to the need for these profit making organisations to recover the monies that have been spent on advertisements. Additionally, consumers may end themselves up buying products or services that they do not actually require in their lives, thanks to the enticing nature of certain highly creative and persuasive advertisements. Also, some advertisements may be manipulated in a way that they look, taste or even smell better than what consumers could actually get their hands on at the end of the day. This could lead to disappointment among the consumers as they realised that the advertisements could have been more misleading or overly exaggerated.

\section{Methodology}

A survey questionnaire will be prepared and passed to the respondents for data collection, hence the employment of quantitative methodology. As a majority (close to 99\%) of the new students intake in July 2018 are of the Malay ethnic, the survey questionnaire has been prepared in dual languages, specifically in English and the Bahasa Melayu. The target respondents aimed would be mainly from two groups, which are the students themselves, and the student's parents. An initial 800 respondents are targeted, and the researcher sets a realistic questionnaire return percentage to $85 \%$, which translates to an expectation of around 680 questionnaire forms would be duly completed and collected back for data analysis. This may be due to the fact that some returned forms may not be fully completed in certain parts.

The survey form has been prepared using Likert scale, ranging from 5 as strongly agree, 4 as merely agreeing, 3 as being neutral, 2 as disagreeing, and 1 for strongly disagreeing. The questionnaire is prepared based on two categories of firstly to review the existing marketing and advertising practices, and secondly for the respondents to recommend refined or new practices that the management of PICOMS could consider in the future.

After the questionnaire forms are returned to the researcher, data analysis will be done using Microsoft Excel. The researcher would then determine the trends of the answers by using charts and graphs to further analyse the outcome of the surveys. These shall then be compared, contrasted and analysed in the results and discussions section.

\section{Results and Discussions}

Surprisingly, all the 800 respondents have fully completed the questionnaires with no blank entries. This is further broken down into 400 students and another 400 parents. So the below results are presented based on 800 effective respondents, stated in both numbers, and in percentages over $100 \%$. The graphs are presented through stacked column charts for the ease of comparing the weightages of each element. 
When it comes to reviewing the current practices of PICOMS, from a bird's eye view it can be seen that most of the respondents are strongly agreeing to the management's practices of using Facebook advertising, the Whatssap platform, as well as CSR initiatives.

Specifically within the Facebook advertising, $94 \%$ of the respondents were strongly agreeing that the management should continue to use this platform to attract their new students every semester. Only a mere 3\% agreed to this, and another 3\% remained neutral. No respondents are disagreeing this practice which only shows the high support that the respondent community has for PICOMS to continue practicing this platform. Facebook advertising has been one of the most utilised social media advertising platform among the business community worldwide and it has proven to be able to generate profitability growths for these organisations. Through targeted advertising methods, Facebook has effective means for PICOMS to reach to those users who are searching for courses such as what PICOMS are offering (Lutze, 2010).

As regards to Whatssap messenger application for smartphones, another whopping 95\% of the total respondents strongly concurred this method as another extremely useful and fruitful results for student recruitment activities. This is followed by $2 \%$ merely agreeing, another $2 \%$ being neutral, and $1 \%$ disagreeing to this statement. This messenger has the capability of forming groups among specific users that the management of PICOMS can specifically segregate according to different biography means. Then the management would keep members of the groups up to date on the latest promotions, courses and happenings around the campus. The ability of the management to constantly be able to reach a large community of users based on their defined interests, age group, and so on would form an effective mean for them to sustain its student recruitment activities every semester.

When it comes to using newspaper as a source of advertisement, surprisingly we are seeing only $30 \%$ of the total respondents strongly agreeing to this fact, followed by $33 \%$ merely agreeing, $17 \%$ being neutral, $14 \%$ disagreeing and $7 \%$ strongly disagreeing for such practice. This could be due to the millennials have realised that the world today is being conquered by digital media and digital advertising practices. Everybody have shifted from traditional printed media such as newspaper and magazines towards digital media. We are also seeing more news readers that are shifting towards digital newspapers rather than continue to purchase traditional physical newspaper copies. Such a phenomenon has shown that the people are no longer sticking to traditional media for their daily readings, and therefore the respondents are advising the management of PICOMS to also switch towards digital advertising such as Facebook and Whatssap and not continuing physical advertisings such as newspapers.

As regards to television, the researcher has again found out that most of the respondents are towards the disagreeing and strongly disagreeing side of opinions. They may also regard television advertising as another form of outdated advertising medium as more users are turning towards internet streaming platforms such as YouTube and Netflix where the users are able to have more freedom in terms of when they would like to watch their shows or movies. Traditional televisions are very rigid in the sense that specific movies are being played within specific timings. If a user misses that period of time, that's it. However platforms such as YouTube and Netflix gives the users their total freedom to watch whatever shows they like at any time of their convenience. That is why the respondents are urging the management of PICOMS to ditch traditional television advertising and look towards what the trends are shifting towards now.

The same goes for radio advertising where the results are showing almost similar trends with television advertising. The respondents may be of the opinion that radio are also as rigid as television in terms of freedom to listen at specific timings. Users nowadays are also shifting towards online radios such as Tune In where they are able to have more freedom too. Therefore the management of PICOMS should also consider ditching their radio advertising practices and go with the trend towards internet streaming radio platforms. 
Also, majority of the respondents are on the against side when it comes to billboard advertising. They believe that the presences of billboards at highways are no longer as attractive to targeted advertising that the digital marketing platforms can offer today. As billboard advertisings targets the general population and do not highlights the contents to consumers who may be potentially interested, this may be one of the disadvantages that the respondents may find wasteful, due to the message may not be able to be passed on to the right audiences despite high costs being paid for such advertising.

The respondents are finding the nature of corporate social responsibilities bearing high degrees of similarities to Whatssap and Facebook in the sense of being an effective way of advertising. Whenever the management of PICOMS are participating in socially responsible activities within the society, they are actually indirectly advertising their courses to their potential customers. Therefore, this has lead $88 \%$ of the total respondents strongly agreeing with this initiative, followed by a minority of $3 \%$ merely agreeing, $5 \%$ being neutral, and another $2 \%$ and $2 \%$ being disagreeing and strongly disagreeing respectively.

\begin{tabular}{|l|l|l|l|l|l|}
\hline In numbers & $\begin{array}{l}\text { Strongly } \\
\text { Agree }\end{array}$ & Agree & Neutral & Disagree & $\begin{array}{l}\text { Strongly } \\
\text { Disagree }\end{array}$ \\
\hline Facebook advertising & 698 & 62 & 39 & 1 & 0 \\
\hline Whatssap messenger & 694 & 53 & 35 & 16 & 2 \\
\hline Newspaper & 262 & 251 & 124 & 108 & 55 \\
\hline Television & 82 & 134 & 128 & 268 & 188 \\
\hline Radio & 98 & 161 & 163 & 199 & 179 \\
\hline Billboards & 53 & 86 & 93 & 325 & 243 \\
\hline CSR initiatives & 641 & 50 & 63 & 35 & 11 \\
\hline
\end{tabular}

Table 1: Review of existing advertising practices in numbers

\begin{tabular}{|l|r|r|r|r|r|}
\hline In percentage \% & Strongly Agree & Agree & Neutral & Disagree & $\begin{array}{c}\text { Strongly } \\
\text { Disagree }\end{array}$ \\
\hline $\begin{array}{l}\text { Facebook } \\
\text { advertising }\end{array}$ & 94 & 3 & 3 & 0 & 0 \\
\hline $\begin{array}{l}\text { Whatssap } \\
\text { messenger }\end{array}$ & 95 & 2 & 2 & 1 & 0 \\
\hline Newspaper & 30 & 33 & 17 & 14 & 7 \\
\hline Television & 8 & 15 & 16 & 35 & 26 \\
\hline Radio & 13 & 18 & 17 & 29 & 23 \\
\hline Billboards & 3 & 7 & 11 & 45 & 34 \\
\hline CSR initiatives & 88 & 3 & 5 & 2 & 2 \\
\hline
\end{tabular}

Table 2: Review of existing advertising practices in percentages 


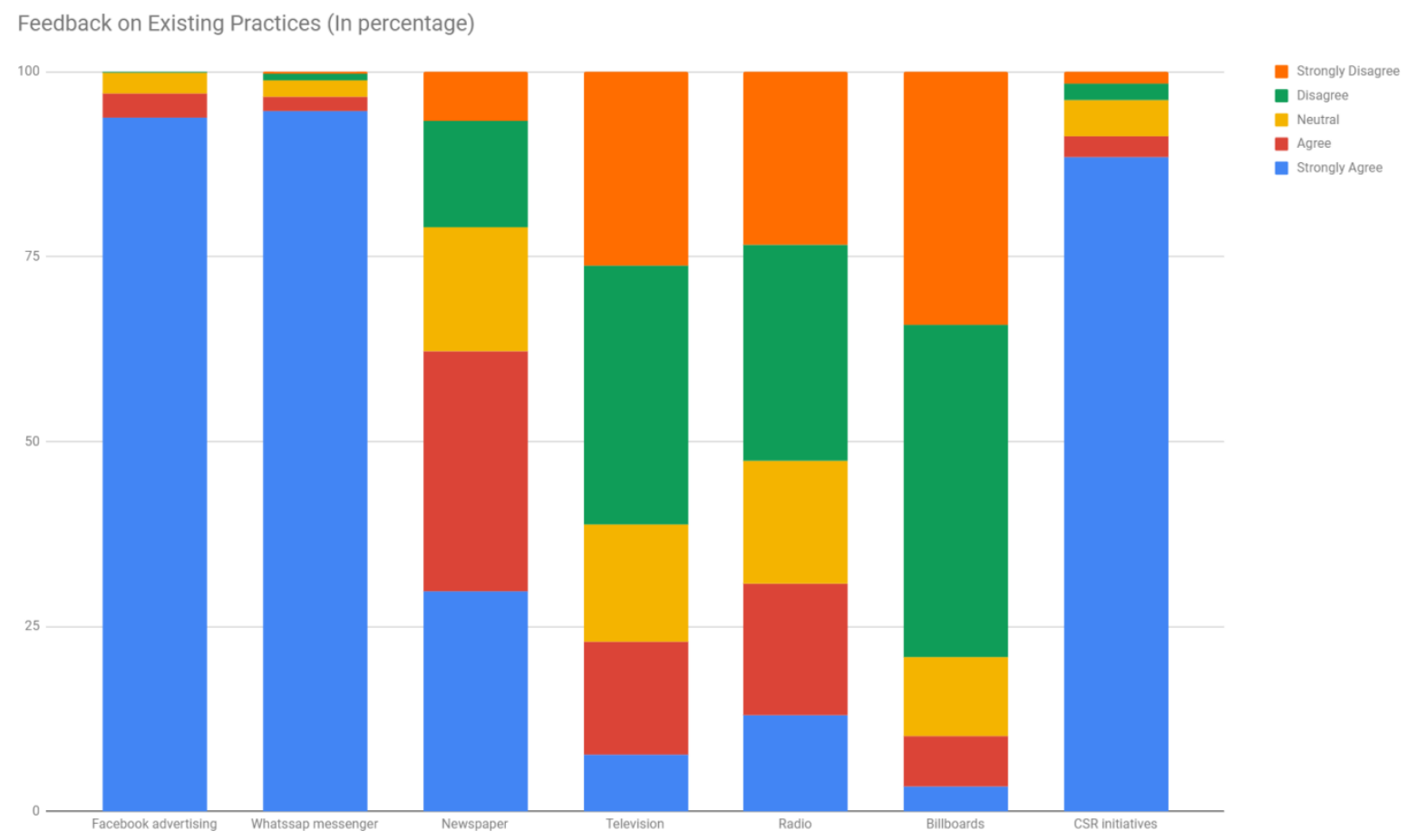

Chart 1: Review of existing practices

As a whole, it can be seen that most of the respondents are on the agreeing side for all of the recommended initiatives.

For Google Adwords advertising, a whopping 95\% of the respondents strongly concurred with this initiative, with another 3\% being merely agreeing, and another $1 \%$ being neutral and a last $1 \%$ disagreeing. Google Adwords is a type of pay per click advertising method that helps the management of PICOMS to target specific customers whenever the customers are searching for courses that they are interested to enroll in, through Google search. And the benefit of this method is, PICOMS only gets billed whenever an interested customer clicked on the advertisement link. It is in fact a very useful advertising method that is both cost efficient and very effective as well as fruitful in being able to reach only interested customers thereby increasing the possibilities of sales for every click done. Therefore, the respondents are highly recommending this method going forward.

As for competitive intelligence activities, 77\% of the respondents strongly agreed that the management of PICOMS to undertake this, followed by $15 \%$ agreeing, and the rest of the $9 \%$ minorities on both the neutral and disagreeing side. The respondents are of the opinion that the management of PICOMS should engage in ethical spying activities on their competitors. This could include collecting the leaflets of their competitors during educational fairs and exhibitions, signing up of periodic newsletters at their competitors' websites, following their competitors' social media channels and so on. These activities could land PICOMS on a better position within the private higher learning industry so that they would able to ensure that they do not lag behind their competitors in light of the ever changing landscape of this competitive industry.

The word of mouth advertising is another possible initiative that the respondents feel that the management of PICOMS should look into. It is after all, free of any possible charges, and has the potential to produce very effective results in terms of sustaining student 
recruitment for PICOMS. A shocking $98 \%$ of the respondents strongly agreed to this, with only the leftover $2 \%$ being merely agreeing. No one became neutral or even disagreed with this statement. When the word is out on the courses or activities that PICOMS are recruiting, people tend to share the very details of the benefits of these courses with their friends and relatives. Such sharing that comes with personal touches will entice potential students more towards joining PICOMS.

When it comes to setting up a blog page and to ensure that the blog is maintained in a way that constant updates are being done every now and then, a majority of $75 \%$ respondents strongly agreed to this. This is followed by $21 \%$ being merely agreeing, $3 \%$ being neutral and $1 \%$ disagreeing. It seems that the respondents believe that customers like to be kept updated on the happenings, activities and promotions that PICOMS are having every now and then. And the best way to present these would be through blogging. Therefore, it is evident that, by maintaining a blog site, it is very likely that the management of PICOMS would be able to expedite its advertising efforts.

Ninety one percent of the respondents strongly agreed that the management should look into the creation of video tutorials as a mean to attract future students. This is followed by six percent of the respondents agreeing, $1 \%$ being neutral and $1 \%$ strongly disagreeing. The respondents believed that potential students need to be walked through on the prospects of the courses and what expectations can they get. All these can be easily done through video tutorials that clearly depicts all the essential info for potential students to sign up with PICOMS.

Search engine optimisation, or better known as SEO, would be another key towards transforming the website of PICOMS into a potential student magnet. PICOMS already has its own website, but the concern is that, whenever potential students search for keywords such as "Diploma in Physiotheraphy Malaysia", or "Diploma in Nursing Science Malaysia"; would PICOMS' website appear in the first few pages of the search engine results? If not, then the recommendations of $97 \%$ respondents who strongly agreed with SEO, as well as another 3\% agreeing, would be correct. The management needs to take steps in ensuring their websites are easily found whenever someone searches for courses that the institution offers.

As regards to utilising LinkedIn as another marketing initiative, $74 \%$ of the respondents strongly agreed to this, followed by $16 \%$ agreeing, $6 \%$ being neutral, $2 \%$ disagreeing and another $2 \%$ strongly disagreeing. As a whole, the respondents recommends that the management of PICOMS utilise LinkedIn as another strategic initiative to attract potential students. This portal essentially links working professionals to organisations, and just a mere presence of PICOMS within the LinkedIn community would mean that PICOMS would be able to significantly lift its reputation as a quality educational service provider in Malaysia.

95\% of the total respondents strongly agreed that the management also adopts affiliate marketing as another strategy to sustain its student recruitment every semester. This is followed by another $3 \%$ of the respondents merely agreeing to this, and the last $2 \%$ being neutral on this. It is obvious that the respondents highly suggest the management to adopt a system whereby recruiters who have successfully recommend PICOMS' courses to others by generating sales would be able to earn commissions in return. This can also mean that by the management offering incentives for student recruiters who successfully recruited students, it is likely that the student recruitment drives would be more successful.

Email marketing would be another good strategy where the management would email their promotions to recipients who are likely to be interested with their courses. 95\% of the respondents strongly concurred with this strategy, followed by another 3\% merely agreeing, and another $1 \%$ being neutral. The respondents also believed in the effectiveness of reaching potential students via email marketing, as this method is another cost-effective way to reach a high number of potential customers. 
Last but not least, the utilisation of YouTube is also highly suggested where $88 \%$ of the total respondents strongly agreed to this, followed by another 5\% merely agreeing, and the last $7 \%$ being neutral. As mentioned previously, the society today has already shifted from traditional televisions towards digital media such as YouTube. And since YouTube has also been inviting advertisements to boost their income, PICOMS ought to take advantage of this to have their courses being advertised on YouTube too. This is because, YouTube also presents itself as a target marketing service provider where certain advertisements will only be played towards certain groups of people according to their demographics. Hence, YouTube would also be another cost-effective method that can produce high profitability in return.

\begin{tabular}{|l|l|l|l|l|l|}
\hline In numbers & $\begin{array}{l}\text { Strongly } \\
\text { Agree }\end{array}$ & Agree & Neutral & Disagree & $\begin{array}{l}\text { Strongly } \\
\text { Disagree }\end{array}$ \\
\hline Google Adwords & 744 & 43 & 5 & 6 & 2 \\
\hline Competitive intelligence & 573 & 141 & 58 & 23 & 5 \\
\hline Word of mouth & 768 & 32 & 0 & 0 & 0 \\
\hline Blogs & 612 & 161 & 20 & 5 & 2 \\
\hline Creating video tutorials & 691 & 73 & 30 & 2 & 4 \\
\hline $\begin{array}{l}\text { Search angine } \\
\text { optimisation affliliate }\end{array}$ & 757 & 41 & 1 & 1 & 0 \\
\hline LinkedIn & 602 & 131 & 42 & 12 & 13 \\
\hline $\begin{array}{l}\text { Creating } \\
\text { programs }\end{array}$ & 748 & 43 & 15 & 0 & 0 \\
\hline Email marketing & 724 & 58 & 18 & 0 & 0 \\
\hline Incentives for recruiters & 72 & 48 & 1 & 0 \\
\hline YouTube & & & & & \\
\hline
\end{tabular}

Table 3: Recommendations of future initiatives in numbers 


\begin{tabular}{|c|c|c|c|c|c|}
\hline In percentage \% & Strongly Agree & Agree & Neutral & Disagree & $\begin{array}{l}\text { Strongly } \\
\text { Disagree }\end{array}$ \\
\hline $\begin{array}{l}\text { Google } \\
\text { Adwords }\end{array}$ & 95 & 3 & 1 & 1 & 0 \\
\hline $\begin{array}{l}\text { Competitive } \\
\text { intelligence }\end{array}$ & 77 & 15 & 6 & 2 & 1 \\
\hline Word of mouth & 98 & 2 & 0 & 0 & 0 \\
\hline Blogs & 75 & 21 & 3 & 1 & 0 \\
\hline $\begin{array}{l}\text { Creating video } \\
\text { tutorials }\end{array}$ & 91 & 6 & 1 & 0 & 1 \\
\hline $\begin{array}{l}\text { Search engine } \\
\text { optimisation }\end{array}$ & 97 & 3 & 0 & 0 & 0 \\
\hline LinkedIn & 74 & 16 & 6 & 2 & 2 \\
\hline $\begin{array}{l}\text { Creating } \\
\text { affliliate } \\
\text { programs }\end{array}$ & 95 & 3 & 2 & 0 & 0 \\
\hline $\begin{array}{l}\text { Email } \\
\text { marketing }\end{array}$ & 95 & 3 & 1 & 0 & 0 \\
\hline $\begin{array}{l}\text { Incentives for } \\
\text { recruiters }\end{array}$ & 92 & 6 & 3 & 0 & 0 \\
\hline YouTube & 88 & 5 & 7 & 0 & 0 \\
\hline
\end{tabular}

Table 4: Recommendations of future initiatives in percentages

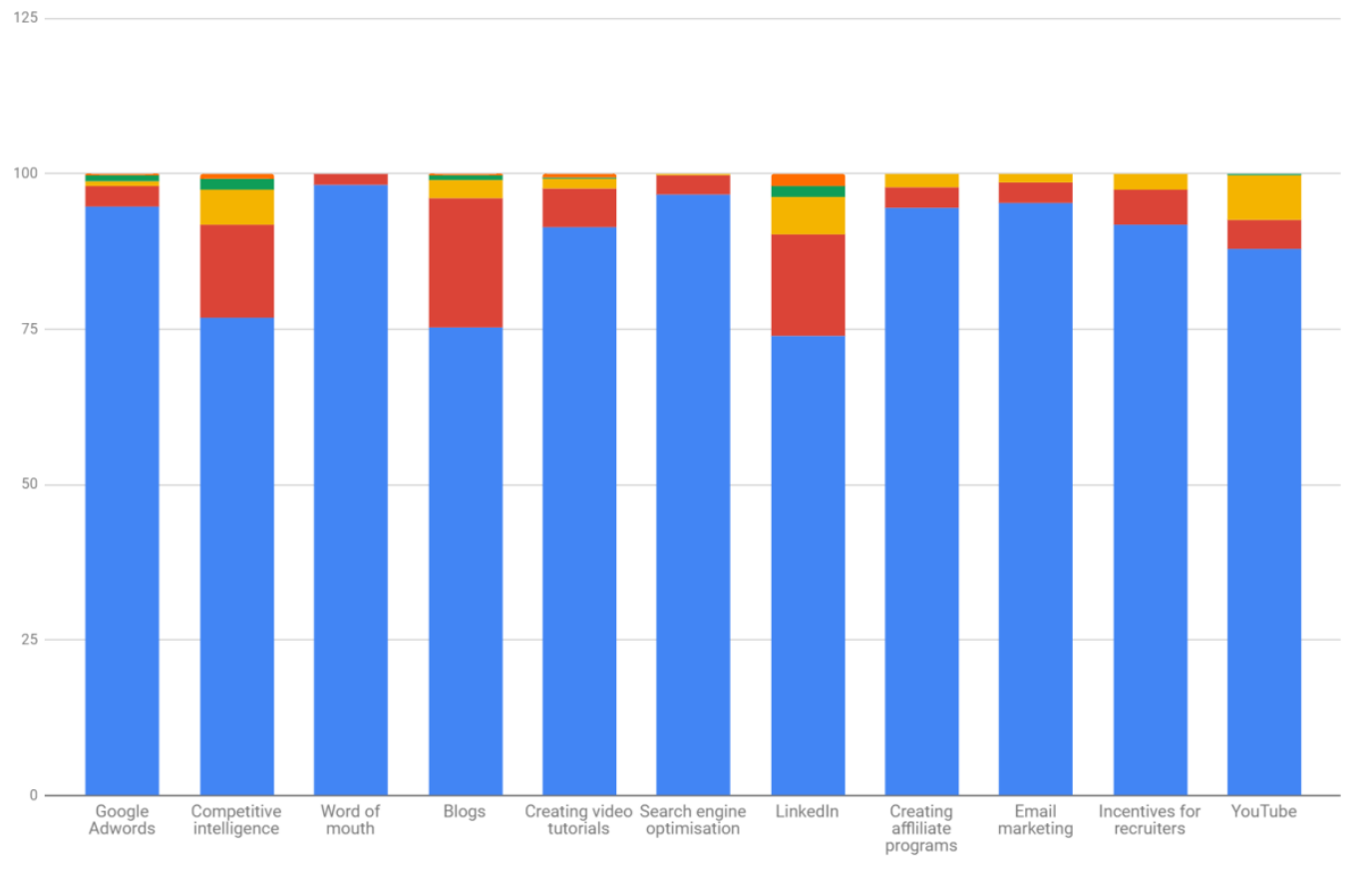

Chart 2: Recommendations for future initiatives 


\section{Conclusions}

In a nutshell, most of PICOM's existing advertising practices, save for digitized ones, are considered less than desired in terms of the effectiveness perceived by the respondents therefore may not be that worth versus the costs spent. It can be seen that, the existing practices that are less effective in giving desired results would be newpaper, radio, television and billboard advertising. Those that are commendable in being effective would be Facebook, Whatssap and CSR initiatives.

Going forward, it is highly suggested that Google Adwords. word of mouth, video tutorial creation, search engine optimisation, affiliate programs creation, email marketing, YouTube and providing incentives for the recruiters are implemented. It is recommended that the management of PICOMS to look seriously at implementing some if not all of the recommended initiatives so as to be able to keep abreast of its competitions and sustain its profitability going forward.

In this research, the researcher faced some limitations. One of it would be the ability to thoroughly examine the data from respondents, which can be more detailed if qualitative methodology is employed. The usage of questionnaire limits the freedom of speech among participants because the respondents can only choose their degree of agreeableness without having the room to explain more. However the advantage of using a pure quantitative methodology would be the ability of the researcher to reach out to a very large population of respondents to gain more effective data and results which cannot be done through qualitative interviews.

Therefore it is highly recommended that future researchers look into combine quantitative with certain degree of qualitative methodology. This could be done by, for example, interviewing some respondents to get more detailed explanations on the possible current versus future marketing strategies. This would definitely improve the quality of research done, in terms of being able to attain a large number of respondents for obtaining quality results, as well as being able to get detailed explanations on the questions.

\section{REFERENCES}

Colvin, M., Heeler, R., \& Thorpe, J. (1980). Developing International Advertising Strategy. Journal of Marketing, 44, pp. 73 -79.

Jager, W. (2007). The Four P's in Social Simulation, A Perspective on How Marketing Could Benefit from the Use of Social Simulation, Journal of Business Research, 60 (8), pp. 868-875

Jefkins, F. (1992) Public Relations. London: Pitman Publishing.

Kotler, P. (2002). Marketing Management Millenium Edition. Boston: Pearson.

Lutze, H. (2010). Using Facebook as a business-building tool. Agency Sales, 40, 46-48.

Starck, K., and Zadeh, S. H. (2013). Marketing within higher education institutions - A case study of two private Thai Universities. Master Thesis in Business Administration, Malardalen University.

Terkan, R. (2014). Importance of Creative Advertising and Marketing According to University Students' Perspective. International Review of Management and Marketing, 4(3), pp. 239-246.

Trehan, M., and Trehan, R. (2010). Advertising and Sales Management. New Delhi: V. K. Enterprises.

Wang, I-F., Chung, G-H., and Kuo, C-T. (2010). A Study of Marketing and Advertising Strategies of Academic Organisations in Taiwan Adult Learning. The Journal of Human Resource and Adult Learning, 6(2), pp. 14-20. 
Wee, V. E. K., and Periyayya, T. (2013). Student Expectations and Branding Strategies among Private Institutions of Higher Education in Malaysia. Malaysian Journal of Chinese Studies, 2(1), pp. 69-81.

Wijaya, L. S., and Krismiyati (2013). Identifying Marketing Public Relations Strategies Implemented in Private Universities for Increasing Students Intake in Central Java - Indonesia. International Refereed Research Journal, 4(2), pp. 43-49.

Wong, A. M-N., and Hamali, J. (2006). Higher education and employment in Malaysia. International Journal of Business and Society, 7(1), pp. 102-120.

\section{AUTHORS}

Datuk Dr Mahamad Zubir bin Seeht Saad, DBA, R. PH. MMPS, B. Pharm (Hons) MBA, Pusrawi International University College of Medical Sciences, datukzubir@picoms.edu.my. 